\title{
Reação do Trigo à Magnaporthe grisea nos Diferentes Estádios de Desenvolvimento
}

\author{
Mauricio A. Arruda*1, Cassiara R. N. C. Bueno*1, Karina C. Zamprogno*1, Norberto A. Lavorenti² \& \\ Alfredo S. Urashima $* * 1$ \\ ${ }^{1}$ Departamento de Biotecnologia Vegetal, Centro de Ciências Agrárias, Universidade Federal de São Carlos, \\ CEP 13600-970, Araras, SP, e-mail: alfredo@dbv.cca.ufscar.br; ${ }^{2}$ Departamento de Tecnologia Agroindustrial e \\ Sócio-economia Rural, CCA, UFSCar, Araras, SP
}

(Aceito para publicação 20/12/2004)

Autor para correspondência: Alfredo S. Urashima

ARRUDA, M.A., BUENO, C.R.N.C., ZAMPROGNO, K.C., LAVORENTI, N.A. \& URASHIMA, A.S. Reação do trigo à Magnaporthe grisea nos diferentes estádios de desenvolvimento. Fitopatologia Brasileira 30:121-126. 2005.

\section{RESUMO}

A brusone em trigo (Triticum aestivum), causada por Magnaporthe grisea, foi relatada pela primeira vez no Paraná em meados da década de 80 , estando atualmente disseminada nos principais estados produtores do país. A relação da resistência à brusone nas folhas e espigas de trigo foi estudada utilizando-se 15 variedades de trigo e três diferentes isolados do fungo. Foram empregados cinco variedades e três isolados de $M$. grisea para estudar a relação entre resistência de espigas e percentagem de infecção das sementes colhidas. Os resultados demonstraram que houve correlação positiva entre suscetibilidade nas folhas no estádio vegetativo e nas espigas. A variedade BH1146 foi a única que apresentou correlação positiva da resistência, pois foi a única a apresentar plântulas resistentes que posteriormente se refletiu numa menor incidência de espigas doentes com menor severidade da doença. Detectou-se correlação altamente significativa entre incidência e severidade da doença nas espigas. As percentagens de sementes infetadas foram menores nas variedades que apresentaram reação resistente nas espigas do que nas variedades suscetíveis.

Palavras-chave adicionais: Pyricularia grisea, Triticum aestivum, brusone, resistência.

\begin{abstract}
Reaction of wheat to Magnaporthe grisea at different stages of host development

The blast of wheat (Triticum aestivum) was first reported in the State of Paraná in 1986 and has now spread to all the major wheat growing areas of Brazil. The relation between leaf and neck blast resistance was studied utilizing three isolates and 15 wheat varieties. The relationship between incidence of blast in wheat spikes and infection of harvested seeds was examined using inoculation tests with three fungal isolates on five wheat cultivars. The varieties showing susceptible reaction at seedling stage were also susceptible to spike infection. The BH1146 was the sole variety resistant at seedling stage, which subsequently produced a significantly lower the incidence and severity of blast. A high positive correlation was observed between incidence and severity of diseased heads. The percentage of infected seeds was less in varieties exhibiting a resistant reaction to spike infection than in susceptible varieties.
\end{abstract}

Additional keywords: Pyricularia grisea, Triticum aestivum, blast, resistance.

\section{INTRODUÇÃO}

O trigo (Triticum aestivum L.) ocupa papel de destaque dentre os cereais produzidos no Brasil, tendo uma importante função econômica e social. Apesar dessa importância, seu potencial não tem sido explorado devidamente. Uma das limitações de maior destaque é o freqüente aparecimento de doenças que causam queda da produtividade, devido às condições propícias para sua ocorrência nas áreas onde esse cereal é cultivado no país. Dentre estas a brusone do trigo, uma doença causada por Magnaporthe grisea (Hebert) Barr. [anamorph Pyricularia grisea (Cooke) Sacc.] e que foi relatada pela primeira vez em meados da década de 80 (Igarashi et al.,

*Bolsista de IC da FAPESP

**Bolsista de JP da FAPESP
1986), vem ocupando um papel de destaque por proporcionar perdas em peso por espiga de até $72,5 \%$, dependendo da época da infecção (Goulart \& Paiva, 2000).

Inúmeros trabalhos vêm sendo realizados com o intuito de minimizar o impacto deste patógeno nessa cultura, incluindo o estudo da eficiência de tratamento químico de sementes (Goulart \& Paiva, 1991), uso de variedades resistentes (Igarashi, 1990; Urashima \& Kato, 1994), de produtos químicos mais eficientes para o seu controle (Urashima \& Kato, 1994; Goulart et al., 1996). Entretanto, pouca pesquisa tem enfocado a resistência da planta do trigo ao fungo causador da brusone em diferentes estádios fenológicos. Essa informação poderia ser utilizada nos programas de melhoramento, previsão da doença e controle químico. Não há informação quanto à relação entre a resistência da planta na fase vegetativa e reprodutiva em trigo. 
M.A. Arruda et al.

O estudo da correlação da resistência no estádio vegetativo e reprodutivo à $M$. grisea em arroz (Oryza sativa L.) tem despertado a atenção desde longa data, comprovada pelas pesquisas realizadas em diferentes partes do mundo. Apesar disso, resultados conflitantes têm sido observados quanto à relação entre resistência da folha e da panícula por vários pesquisadores (Rangaswami et al, 1958; Ou \& Nuque, 1963; Willis et al, 1968; Bonman, 1992). Bonman et al. (1989) observaram que variedades suscetíveis ao ataque de $M$. grisea na folha foram resistentes na panícula. Mais recentemente, Roumen (1992a, 1992b), Prabhu \& Fillipi (1995), Yang et al. (1998) observaram maior resistência das folhas nas plantas adultas em relação às mais jovens, mas nenhuma inferência se a resistência da planta na fase vegetativa vai ser igual à resistência da panícula foi feita.

Outro aspecto pouco enfocado no patossistema $T$. aestivum-M. grisea se refere à relação entre a resistência da espiga do trigo e a presença do fungo nas sementes colhidas. $\mathrm{O}$ uso de sementes sadias é uma das estratégias mais importantes para o controle da brusone já que sementes contaminadas são importante fonte de inóculo primário da doença para novas áreas (Goulart \& Paiva, 1990; Urashima et al., 1999). No único estudo a este respeito, Goulart et al. (1995) observaram uma correlação direta entre incidência de brusone em espigas de trigo no campo e a percentagem de sementes colhidas com presença de $M$. grisea. No entanto, nenhuma informação sobre a relação entre severidade da doença na espiga e percentagem de sementes foi feita.

Este trabalho visou determinar a reação da planta de trigo no estádio vegetativo e reprodutivo e a relação entre a resistência das plântulas, incidência e severidade de doença nas espigas e a percentagem de sementes infetadas colhidas.

\section{MATERIAL E MÉTODOS}

\section{Hospedeiro}

As variedades de trigo utilizadas neste trabalho foram gentilmente cedidas pela Embrapa - Trigo, Embrapa - CPAO, Iapar, IAC, Coodetec e multiplicadas no CCA - UFSCar. Essas variedades compreenderam BR 17, BR 18, BR 21, BR 31, BR 40, BH 1146, Ocepar 7, Ocepar 16, Ocepar 22, Embrapa 10, Iapar 3, Iapar 17, CNT 8, Anahuac e OR 1. Sementes prégerminadas foram plantadas em copos de poliestileno de 200 $\mathrm{ml}$ em solo procedente de horizonte $\mathrm{O}$ de mata do CCA e inoculadas após atingirem estádio de três-quatro folhas. Sementes de trigo, que foram inoculadas no estádio reprodutivo,

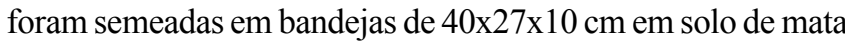
utilizando-se 30-35 sementes pré-germinadas por bandeja e se tornaram aptas para a inoculação quando atingiram $70 \%$ de florescimento.

\section{Isolados}

Os isolados de M. grisea PR01-23, PR05-11 e PR06-03 foram utilizados na realização deste trabalho. Todos os isolados foram obtidos monosporicamente de diferentes de diferentes variedades, assim o isolado PR01-23 foi obtido de espiga infetada da variedade OR1 coletada em Londrina-PR em agosto de 1998; o isolado PR05-11 da variedade Ocepar 22 coletada em Palotina, em outubro de 1998 e o isolado PR06-03 da variedade CD-104 coletada em Cascavel em setembro de 1998. Todos esses isolados se encontravam conservados em sementes de cevada autoclavadas e mantidas a $5{ }^{\circ} \mathrm{C}$ e baixa umidade no Laboratório de Microbiologia Agrícola e Molecular do CCAUFSCar. Cada isolado foi escolhido com base na reação diferencial em plântulas de variedades de trigo. Assim, por exemplo, o isolado PR 01-23 causou reação de suscetibilidade nas variedades Embrapa10, Anahuac e Ocepar7 e reação de resistência nas variedades BR18, BR21 e CNT8.

\section{Preparação do inóculo e inoculação}

Os isolados para inoculação foram multiplicados a partir das sementes colonizadas de cevada em placas de aveia por 20 dias à temperatura de $25^{\circ} \mathrm{C}$. Após esse período, o micélio aéreo foi retirado com rodo de vidro e água destilada autoclavada e, posteriormente, colocados em câmara sob luz fluorescente constante à temperatura ambiente. Após quatro dias, os esporos foram desalojados com água destilada e filtrados em lenço de papel. O volume de suspensão para a inoculação de cada conjunto foi de $50 \mathrm{ml}$ com concentração variando de 1-6 $\times 10^{5}$ esporos $/ \mathrm{ml}$ acrescentado de Tween 20 a $0,01 \%$, como espalhante. As inoculações foram feitas com pulverizadores manuais, tendo as plantas permanecido $18-24 \mathrm{~h}$ em saco plástico a uma temperatura entre $24-28{ }^{\circ} \mathrm{C}$.

Por ocasião da inoculação de trigo no estádio reprodutivo, duas situações distintas ocorreram, mas sempre empregando a mesma metodologia de inoculação empregada em plântulas. Na primeira, com variedades suscetíveis no estádio de plântula, a inoculação foi feita no conjunto formado de plantas no estádio reprodutivo juntamente com plântulas da mesma variedade como controle. Para plântulas resistentes, o conjunto constava de planta de trigo no estádio reprodutivo juntamente com plântula da mesma variedade no estádio vegetativo e outra variedade suscetível no estádio vegetativo, atuando como controle. Cada isolado foi repetido quatro vezes.

\section{Avaliações}

A avaliação da reação das plântulas inoculadas quanto à brusone foi feita uma única vez, sete dias após a inoculação seguindo-se a mesma classificação empregada por Urashima \& Kato (1994). Os tipos de lesões foram classificados em cinco categorias: $0=$ sem sintoma visível da doença; $1=$ lesões minúsculas do tamanho cabeça de alfinete; $2=$ manchas amarronzadas, embora possa haver variação quanto à coloração, sem centro discernível; 3 = pequenas lesões com formato de olho e centro cinza; 4 = lesões típicas de brusone, elíptica e centro cinza. Lesões tipo 0, 1, 2 foram consideradas resistentes porque não esporularam quando submetidas às condições favoráveis, enquanto lesões 3 e 4 foram consideradas suscetíveis devido à sua esporulação.

O exame da reação do trigo no estádio reprodutivo foi feito através de dois parâmetros: incidência e severidade, avaliados 21 dias após inoculação. A incidência foi determinada 
pelo número de espigas apresentando sintomas da doença, expressa em porcentagem. $\mathrm{O}$ grau de severidade da doença foi avaliado levando-se em consideração a porcentagem da área da espiga necrosada, devido ao ataque do patógeno, atribuindose notas: nota $0=$ espiga sem doença visível; nota $1=$ menos de $5 \%$ da espiga necrosada; nota $2=5-30 \%$ necrosada; nota 3 $=30-50 \%$; nota $4=+50 \%$; nota $5=100 \%$ da espiga necrosada.

\section{Sanidade de sementes}

O exame de sanidade de sementes foi baseado na metodologia empregada por Goulart et al. (1995). Amostras de 50 sementes cada foram coletadas aleatoriamente de espigas resistentes e suscetíveis de diferentes variedades. Espigas consideradas resistentes foram aquelas que não apresentavam sintoma visual de brusone ao passo que as consideradas suscetíveis foram aquelas com sintoma visual da doença. Essas amostras foram colocadas em placa de Petri com três folhas umedecidas de papel de filtro esterelizadas e incubadas a 21 ${ }^{\circ} \mathrm{C}$ e fotoperíodo de $12 \mathrm{~h}$. No dia seguinte, submetidas à temperatura de $-20^{\circ} \mathrm{C}$ por $24 \mathrm{~h}$ para destruição da germinação. Após esse período, as placas foram incubadas a $21^{\circ} \mathrm{C}$ em igual fotoperíodo por três-quatro dias. A presença de esporos assexuais de $M$. grisea foi examinada em cada semente, individualmente, com auxílio de microscópio. Os dados foram expressos em porcentagem de infecção e no experimento foram utilizadas quatro repetições.

\section{Análise Estatística}

Para a análise estatística foi utilizado o programa estatístico SAS (Statistical Analysis System). A relação entre a reação das variedades de trigo no estádio vegetativo e reprodutivo quando, inoculadas com isolados de $M$. grisea foi examinada através do teste Qui-quadrado $\left(\chi^{2}\right)$ de associação entre variedades de trigo e os tipos de infecção nas espigas, ao nível de 5\% probabilidade. Para análise da incidência de brusone nas espigas de diferentes variedades de trigo, os dados originais foram submetidos à analise de variância e as médias comparadas pelo teste Tukey $(\mathrm{p}=0,05)$. Para o estudo da relação entre resistência da espiga do trigo e a presença de $M$. grisea nas sementes colhidas, os dados originais foram transformados em arco seno $\sqrt{ } \%$ infecção/100 e analisados pelo teste Tukey, ao nível de $5 \%$ de probabilidade.

\section{RESULTADOS}

De acordo com a reação das variedades de trigo nos estádios vegetativo e reprodutivo, representado pela incidência de espigas afetadas e severidade da doença, aos isolados de M. grisea PR01-23, PR05-11 e PR06-03, respectivamente (Tabelas 1, 2 e 3), os resultados mostraram que existiu reação diferencial das plântulas de trigo aos isolados do fungo nas inoculações no estádio vegetativo. Reação considerada resistente ou incompatível foi observada nas variedades BR18, CNT8 e BR21 e reação suscetível ou compatível nas variedades Anahuac, Embrapa10 e Ocepar7 quando inoculadas com o isolado PR01-23 (Tabela 1). O isolado PR05-11 causou reação de compatibilidade em plântulas das variedades Anahuac, Iapar17 e BR17 e de incompatibilidade em Iapar3, BR18 e BR31 (Tabela 2), ao passo que Ocepar16, Ocepar22 e BR40 foram suscetíveis e OR1 e BH1146 resistentes ao isolado PR0603 (Tabela 3).

No estádio reprodutivo, todas as variedades mostraram espigas com sintomas da doença, independentemente dos isolados empregados. No entanto, incidência alta, variando de 88.25 a $100 \%$ de espigas infetadas foi observada nas variedades Anahuac, Embrapa10, BR18, Ocepar7, Iapar17, BR17, Iapar3, Ocepar16, Ocepar22 e BR40 (Tabelas 1, 2 e $3)$. Em outras variedades como BR21 (30,99\%, Tabela 1), BR31 (36,73\%, Tabela 2) e BH1146 (9,86\%, Tabela 3) a incidência foi baixa. Embora essa diferença na incidência de espigas doentes nessas variedades tenha sido bastante acentuada, a análise estatística revelou que somente BH1146 apresentou diferença significativa estatisticamente, com níveis menores de incidência que as demais variedades estudadas. Esses resultados indicaram que essa variedade, que mostrou reação incompatível no estádio de plântula, apresentou incidência da doença significativamente menor.

A variedade BR18 foi, juntamente com Anahuac, aquelas cuja reação foi examinada com dois isolados distintos de M. grisea. No estádio de plântulas, 'Anahuac' foi suscetível a ambos os isolados ao passo que 'BR18' foi resistente. No entanto, essas variedades apresentaram reação semelhante no estádio reprodutivo, visto que alta incidência da doença ocorreu em ambas, independentemente do isolado empregado. Assim como BR18, outras variedades que foram resistentes no estádio vegetativo, mas que apresentaram alta incidência de espigas doentes incluíram 'CNT8', 'BR21' (Tabela 1), 'Iapar3', 'BR31' (Tabela 2), 'OR1' (Tabela 3).

Nas inoculações com o isolado PR01-23, nenhuma

TABELA 1 - Grau de severidade e incidência de brusone nas espigas e reação no estádio vegetativo de variedades de trigo (Triticum aestivum) ao isolado PR01-23 de Magnaporthe grisea

\begin{tabular}{|c|c|c|c|c|c|c|c|c|}
\hline \multirow{3}{*}{ Variedade } & \multicolumn{7}{|c|}{ Espiga } & \multirow{3}{*}{$\begin{array}{c}\text { Folha } \\
\text { Reação nas } \\
\text { Plântulas*** }\end{array}$} \\
\hline & \multicolumn{6}{|c|}{ Severidade* } & \multirow{2}{*}{ Incidência } & \\
\hline & $\mathbf{0}$ & 1 & 2 & 3 & 4 & 5 & & \\
\hline Anahuac & 0 & 2 & 5 & 5 & 6 & 20 & $100 \mathrm{a}$ & 4 \\
\hline Embrapa10 & 0 & 1 & 1 & 6 & 4 & 42 & $100 \mathrm{a}$ & 4 \\
\hline Ocepar7 & 7 & 5 & 2 & 2 & 10 & 37 & $88,89 a$ & 4 \\
\hline BR18 & 0 & 1 & 4 & 4 & 9 & 31 & $100 \mathrm{a}$ & 1 \\
\hline CNT8 & 32 & 0 & 0 & 3 & 5 & 27 & $52,24 \mathrm{a}$ & 1 \\
\hline BR21 & 49 & 6 & 1 & 0 & 0 & 15 & $30,99 \mathrm{a}$ & 1 \\
\hline
\end{tabular}

*nota $0=$ espiga sem doença visível; nota $1=$ menos de $5 \%$ da espiga necrosada; nota $2=5-30 \%$ necrosada; nota $3=30-50 \% ;$ nota $4=+50 \% ;$ nota $5=100 \%$ da espiga necrosada;

** 0 = sem sintoma visível da doença; 1 = lesões minúsculas do tamanho cabeça de alfinete; 2 = manchas amarronzadas, embora possa haver variação quanto à coloração, sem centro discernível; 3 = pequenas lesões com formato de olho e centro cinza; 4 = lesões típicas de brusone, elíptica e centro cinza;

C.V. para incidência $=33,93$. Valores seguidos pela mesma letra na coluna, não diferiram significativamente entre si pelo teste de Tukey $(\mathrm{P}=0,05)$;

Valor Qui-Quadrado $\left(\chi^{2}\right)=180,7^{* *} \operatorname{com} 25$ g.l.;

Correlação incidência/severidade $=0,939^{* *}$. 
TABELA 2 - Grau de severidade e incidência de brusone nas espigas e reação no estádio vegetativo de variedades de trigo (Triticum aestivum) ao isolado PR05-11 de Magnaporthe grisea

\begin{tabular}{|c|c|c|c|c|c|c|c|c|}
\hline \multirow{3}{*}{ Variedade } & \multicolumn{7}{|c|}{ Espiga } & \multirow{3}{*}{$\begin{array}{l}\text { Folha } \\
\text { Reação nas } \\
\text { plântulas * }\end{array}$} \\
\hline & \multicolumn{6}{|c|}{ Severidade ${ }^{*}$} & \multirow{2}{*}{ Incidência } & \\
\hline & $\mathbf{0}$ & 1 & 2 & 3 & 4 & 5 & & \\
\hline Anahuac & 2 & 2 & 1 & 2 & 9 & 54 & $97,14 a$ & 4 \\
\hline Iapar17 & 7 & 14 & 8 & 3 & 9 & 20 & $88,52 \mathrm{a}$ & 4 \\
\hline BR17 & 9 & 8 & 7 & 4 & 15 & 18 & $85,25 \mathrm{a}$ & 3 \\
\hline Iapar3 & 8 & 4 & 3 & 3 & 7 & 37 & $87,10 \mathrm{a}$ & 0 \\
\hline BR18 & 7 & 2 & 0 & 3 & 3 & 33 & $85,42 \mathrm{a}$ & 0 \\
\hline BR31 & 31 & 3 & 2 & 4 & 3 & 6 & $36,73 \mathrm{a}$ & 1 \\
\hline
\end{tabular}

* nota $0=$ espiga sem doença visível; nota $1=$ menos de $5 \%$ da espiga necrosada nota $2=5-30 \%$ necrosada; nota $3=30-50 \%$; nota $4=+50 \%$; nota $5=100 \%$ da espiga necrosada;

$* * 0$ = sem sintoma visível da doença; 1 = lesões minúsculas do tamanho cabeça de alfinete; 2 = manchas amarronzadas, embora possa haver variação quanto à coloração, sem centro discernível; 3 = pequenas lesões com formato de olho e centro cinza; 4 = lesões típicas de brusone, elíptica e centro cinza;

C.V. para incidência $=26,09$. Valores seguidos pela mesma letra na coluna, não diferiram significativamente entre si pelo teste de Tukey $(\mathrm{P}=0,05)$

Valor Qui-Quadrado $\left(\chi^{2}\right)=150,0^{* *} \operatorname{com} 25$ g.l.;

Correlação incidência/severidade $=0,903^{* *}$.

TABELA 3 - Grau de severidade e incidência de brusone nas espigas e reação no estádio vegetativo de variedades de trigo (Triticum aestivum) ao isolado PR06-03 de Magnaporthe grisea

\begin{tabular}{|c|c|c|c|c|c|c|c|c|}
\hline \multirow{3}{*}{ Variedade } & \multicolumn{7}{|c|}{ Espiga } & \multirow{3}{*}{$\begin{array}{c}\text { Folha } \\
\text { Reação nas } \\
\text { plântulas }\end{array}$} \\
\hline & \multicolumn{6}{|c|}{ Severidade* } & \multirow{2}{*}{ Incidência } & \\
\hline & 0 & 1 & 2 & 3 & 4 & 5 & & \\
\hline Ocepar16 & 2 & 9 & 0 & 9 & 19 & 20 & $96,61 \mathrm{a}$ & 4 \\
\hline Ocepar22 & 3 & 1 & 3 & 5 & 15 & 54 & $96,30 \mathrm{a}$ & 4 \\
\hline BR40 & 2 & 3 & 4 & 2 & 10 & 26 & $95,74 \mathrm{a}$ & 4 \\
\hline OR1 & 25 & 17 & 11 & 6 & 6 & 6 & $64,79 \mathrm{ab}$ & 0 \\
\hline BH1146 & 64 & 0 & 0 & 0 & 0 & 7 & $9,86 \mathrm{~b}$ & 0 \\
\hline
\end{tabular}

*nota $0=$ espiga sem doença visível; nota $1=$ menos de $5 \%$ da espiga necrosada; nota $2=5-30 \%$ necrosada; nota $3=30-50 \% ;$ nota $4=+50 \% ;$ nota $5=100 \%$ da espiga necrosada;

$* * 0=$ sem sintoma visível da doença; $1=$ lesões minúsculas do tamanho cabeça de alfinete; 2 = manchas amarronzadas, embora possa haver variação quanto à coloração, sem centro discernível; $3=$ pequenas lesões com formato de olho e centro cinza; 4 = lesões típicas de brusone, elíptica e centro cinza;

C.V. para incidência $=23,42 \%$. Valores seguidos pela mesma letra na coluna, não diferiram significativamente entre si pelo teste de Tukey $(\mathrm{P}=0,05)$;

Valor Qui-Quadrado $\left(\chi^{2}\right)=274,7^{* *} \operatorname{com} 20$ g.l.;

Correlação incidência/severidade $=0,909^{* *}$.

variedade se destacou em relação a incidência de espigas infetadas. A variedade BR21, que apresentou resistência no estádio vegetativo, também mostrou severidade da doença nas espigas significativamente menor. Por outro lado, 'CNT8' e 'BR18' que foram resistentes no estádio de plântulas apresentaram grande número de espigas totalmente danificadas (lesão nota 5, Tabela 1). Com relação ao isolado PR05-11, a variedade BR31 mostrou grande número de espigas sem sintomas visíveis da doença (nota 0) que acarretou numa menor severidade da doença. As variedades Iapar3 e BR18, resistentes na plântula, apresentaram espigas completamente infetadas (lesão 5) em número igual às variedades mais suscetíveis (Tabela 2). A variedade BH1146 apresentou reação resistente nas plântulas como nas espigas ao isolado PR06-03. De todas as variedades testadas foi a única que apresentou índices de correlação positiva entre resistência no estádio vegetativo e reprodutivo, tanto no parâmetro incidência quanto severidade da doença.

A correlação entre a incidência e severidade da doença nas espigas foi altamente significativa $(r=0,903 ; p \leq 0,01)$, considerando dados de inoculação com todos os três isolados (Tabelas 1, 2 e 3).

A relação entre resistência das espigas de trigo à brusone e à presença do patógeno nas sementes colhidas (Tabela 4) evidenciaram claramente que espigas sem sintoma visual da doença foram as que apresentaram as menores porcentagens de sementes infetadas, diferindo significativamente das sementes colhidas de espigas com sintomas da doença. Dentre as duas variedades consideradas resistentes, a BH1146 apresentou porcentagem de sementes infetadas significativamente menor que BR21.

\section{DISCUSSÃO}

Os dados aqui obtidos nesse trabalho demonstraram que houve uma correlação positiva entre suscetibilidade das variedades no estádio vegetativo e reprodutivo à brusone, pois todas aquelas que foram suscetíveis quando plântulas também tiveram alta incidência de espigas doentes. Esses dados coincidem com as observações de Prabhu et al. (1996) em brusone de arroz, embora no patossistema $O$. sativa- $M$. grisea haja casos de variedades que foram suscetíveis nas folhas e que se tornaram resistentes na espiga (Bonman et al. 1989).

Por outro lado, em relação à resistência ocorreu variação da resposta das variedades entre os estádios vegetativo e reprodutivo. Na maioria dos casos não houve correlação positiva entre resistência de plântulas e de espigas, pois variedades resistentes no estádio vegetativo, como por exemplo, 'BR18' tiveram alta incidência de espigas doentes (Tabelas 1, 2, 3). Essa variedade tem se sobressaído pelo seu desempenho em ensaios de avaliação de resistência em Goiás

TABELA 4 - Reação de espigas das variedades de trigo (Triticum aestivum) inoculadas com diferentes isolados de Magnaporthe grisea e porcentagem de sementes infetadas

\begin{tabular}{lccc}
\hline \hline Variedade & Isolado & Reação da espiga & $\begin{array}{c}\text { Porcentagem } \\
\text { infecção }\end{array}$ \\
\hline BH1146 & PR01-23 & Resistente & $1 \mathrm{a}^{*}$ \\
BR21 & PR01-23 & Resistente & $12 \mathrm{~b}$ \\
Embrapa10 & PR01-23 & Suscetível & $48 \mathrm{c}$ \\
Anahuac & PR05-11 & Suscetível & $33 \mathrm{c}$ \\
Ocepar22 & PR06-03 & Suscetível & 52c \\
\hline
\end{tabular}

C.V. $=23,13$

*Valores seguidos pela mesma letra na coluna, não diferiram significativamente entre si pelo teste de Tukey $(\mathrm{P}=0,05)$ 
Reação do trigo à Magnaporthe grisea nos diferentes estádios de desenvolvimento

(Silva et al., 2003), sendo ainda bastante cultivada em muitas regiões do Paraná e Mato Grosso do Sul. Dados do presente estudo mostraram que severas perdas de produtividade podem ocorrer com essa variedade em muitas regiões do estado do Paraná, especialmente Londrina e Palotina que foram os locais de origem dos isolados que causaram sintomas severos de brusone nas panículas. Essa diferença nos resultados entre os dois estudos pode ser atribuída a alta variabilidade dos isolados que compõem a população do patógeno (Urashima et al., 1999). A variedade BH1146 foi a única, das 15 estudadas, que apresentou correlação positiva entre resistência no estádio vegetativo e reprodutivo. Essa variedade mostrou-se resistente quando plântula que se refletiu, posteriormente, numa menor incidência da doença nas espigas.

A variação na correlação da resistência em função da variedade aqui verificada também foi observada na brusone do arroz conforme Kato \& Sasaki (1974). Esses pesquisadores detectaram variedades onde glumas e aurículas foram infetadas por raças do fungo incapazes de colonizar folhas, ao passo que para Ou \& Nuque (1963) resistência de folha e resistência da panícula estão aparentemente correlacionadas. Também não existe consenso dessa correlação quando se examinou resistência parcial já que correlação positiva foi observada por Ahn \& Rubiano (1984) enquanto Hwang et al. (1987) detectaram variedades cujas plântulas foram suscetíveis e que, posteriormente, tiveram resistência na panícula no campo. Estudo mais recente demonstrou que genes diferentes conferem resistência da folha e do pescoço à brusone em variedades indica de arroz (Zhuang et al., 2002), demonstrando origem genética para a diferença nas resposta das folhas e do pescoço.

O estudo da correlação entre resistência na fase vegetativa e reprodutiva à $M$. grisea do presente trabalho empregou resistência raça-específica. Para esse tipo de estudo, os ensaios foram realizados em casas de vegetação, sob condições controladas, acarretando num menor número de variantes externos, evitando-se assim, problemas como diferenças nas épocas de florescimento das variedades, desconhecimento da quantidade de inóculo e raças do fungo presente no campo por ocasião da infecção, variação das condições climáticas, problemas esses que foram enfrentados pelas pesquisas anteriores quando avaliaram resistência parcial no campo (Bonman et al., 1989, Prabhu et al., 1996).

Diferença na reação de trigo em função do estádio de desenvolvimento da cultura já havia sido observada anteriormente (Urashima \& Kato, 1998) que havia sugerido a necessidade de se avaliar, além da reação das plântulas, o estádio reprodutivo num programa de seleção e melhoramento de variedades. O presente estudo além de reforçar essa necessidade, demonstra que material suscetível na fase de plântula pode ser descartado, pois, não existiu nenhuma variedade suscetível na fase vegetativa que se tornou resistente posteriormente produzindo espigas sadias. Além disso, como nem todas as variedades consideradas resistentes na fase vegetativa foram resistentes no estádio reprodutivo, a necessidade de se avaliar a resistência por ocasião da formação das espigas torna o processo de seleção torna-se extremamente laborioso mas de importância fundamental.

A maioria das variedades mostrou alta suscetibilidade das espigas à brusone. Esse fato é preocupante devido à falta de resistência das variedades atualmente cultivadas e reforça antigas observações que já enfatizavam a gravidade da brusone para a triticultura brasileira devido à suscetibilidade apresentada pelas variedades por ocasião da formação de grãos (Urashima \& Kato, 1994; Goulart et al., 1995).

Para o estudo da resistência de variedades no estádio reprodutivo da presente investigação, a severidade da doença também foi analisada por constituir-se num parâmetro mais importante que a indicação simples da presença/ausência da doença. Nesse quesito, as variedades BR21, BR31 e BH1146 apresentaram índices significativamente menores de perda de grãos. Todas essas foram resistentes no estádio vegetativo. Assim, embora não tenha havido relação direta entre resistência de plântula e de espiga, observou-se relação inversa, qual seja, correlação positiva entre resistência do estádio reprodutivo e vegetativo visto que as variedades que apresentaram menores índices de incidência de brusone no estádio reprodutivo foram aquelas que apresentaram plântulas resistentes.

Dentre as variedades estudadas, 'BH1146' foi a que apresentou melhor comportamento geral, com severidade significativamente baixa, sendo a única que mostrou incidência significativamente menor, além de serem resistentes no estádio vegetativo. Essa variedade também mostrou comportamento superior de acordo com Barros (1989) num estudo realizado em quatro diferentes locais do estado de São Paulo e por Goulart et al. (1995) num estudo de dois anos com 21 genótipos de trigo. Essas características indicam que essa variedade possui genes de resistência que poderiam ser úteis em cruzamentos nos programas de melhoramento.

Dados do presente estudo, além de confirmar a necessidade de os programas de melhoramento enfocarem também a resistência de espigas, mostrou que a seleção pode ser realizada através da incidência de espigas doentes, pois, existiu correlação altamente significativa com severidade. Trabalho de seleção envolvendo severidade é dificultado pela necessidade de treinamento e uniformidade dos critérios para se detectar o nível de doença, que pode variar entre indivíduos, ao passo que incidência é um parâmetro que não apresenta essas particularidades.

As sementes com a menor porcentagem de infecção por M. grisea foram obtidas de espigas que não apresentaram sintomas visuais da doença indicando que a simples seleção visual das espigas se mostrou eficiente para seleção de sementes sadias. No entanto, o exame laboratorial de sanidade de sementes continua sendo imprescindível para se ter a garantia de que a semente não vai ser fonte de inóculo primário de brusone numa nova área, pois, o exame visual não permitiu identificar diferença de infecção dentre as espigas consideradas sadias. A porcentagem de infecção de sementes detectada numa espiga considerada sadia visualmente não poderia evitar morte de plântulas por M. grisea, visto que Goulart \& Paiva (1991) detectaram transmissão do patógeno para plântulas da ordem de $2,9 \%$, em condições de campo, num lote de sementes 
M.A. Arruda et al.

de trigo com 11,5\% de infecção, infecção similar à apresentada pela variedade BR21. Além disso, a porcentagem de infecção detectada em espigas dessa variedade, considerada resistente, foi acima do padrão de tolerância de $M$. grisea em sementes certificadas e fiscalizadas (Machado, 1994). Inversamente, sementes com porcentagens elevadas de infecção foram provenientes de variedades com alta incidência da doença nas espigas confirmando que a condenação de campos de produção de sementes de variedades suscetíveis pode ser baseada na inspeção visual da doença no campo.

As porcentagens de infecção encontradas nas variedades foram elevadas porque não ocorreu perda por prélimpeza nem a eliminação das sementes chochas e mal formadas, fenômeno comum quando se realiza o beneficiamento e processamento mecânico.

\section{REFERÊNCIAS BIBLIOGRÁFICAS}

AHN, S.W. \& RUBIANO, M. Relationship between susceptibility to leaf blast (Bl) and panicle Bl severity. International Rice Research Newsletter 9:13. 1984. (Abstract)

BARROS, B.C. Reação de variedades de trigo à brusone em condições de campo. Summa Phytopathologica 15:21. 1989. (Resumo)

BONMAN, J.M. Durable resistance to rice blast disease environmental influences. Euphytica 63:115-123. 1992.

BONMAN, J.M., ESTRADA, B.A. \& BANDONG, J.M. Leaf and neck blast resistance in tropical lowland rice varieties. Plant Disease 73:388-390. 1989.

GOULART, A.C.P. \& PAIVA, F.A. Transmissão de Pyricularia grisea através de sementes de trigo (Triticum aestivum). Fitopatologia Brasileira 15:359-362. 1990.

GOULART, A.C.P. \& PAIVA, F.A. Controle de Pyricularia oryzae e Helminthosporium sativum pelo tratamento de sementes de trigo com fungicidas. Pesquisa Agropecuária Brasileira 26:1983-1988. 1991.

GOULART, A.C.P. \& PAIVA, F.A. Perdas no rendimento de grãos de trigo causadas por Pyricularia grisea, nos anos de 1991 e 1992, no Mato Grosso do Sul. Summa Phytopathologica 26:279-282. 2000.

GOULART, A.C.P., PAIVA, F.A. \& ANDRADE, P.J.M. Relação entre a incidência da brusone de trigo e a presença de Pyricularia grisea nas sementes colhidas. Fitopatologia Brasileira 20:184-189. 1995.

GOULART, A.C.P., PAIVA, F.A., MELO FILHO, G.M., \& RICHETTI, A. Efeito da época e do número de aplicações dos fungicidas tebuconazole e mancozeb no controle da brusone (Pyricularia grisea) do trigo: viabilidade técnica e econômica. Fitopatologia Brasileira 21:381-87. 1996.

HWANG, B.K., KOH, Y.J. \& CHUNG, H.S. Effect of adult-plant resistance on blast severity and yield of rice. Plant Disease 71:10351038. 1987.

IGARASHI, S. Update on wheat blast (Pyricularia oryzae) in Brazil. In: Saunders, D.A. (Ed.) Proceeding of the International ConferenceWheat for the nontraditional warm areas. 1990. Mexico, Mexico: CIMMYT, 1990. pp.480-83.
IGARASHI, S., UTIAMADA, C.M., IGARASHI, L.C., KAZUMA, A.H. \& LOPES, R.S. Pyricularia em trigo. 1. Ocorrência de Pyricularia sp. no estado do Paraná. Fitopatologia Brasileira 11:351352. 1986.

KATO, H. \& SASAKI, T. Epidemiological studies of rice blast disease, with special reference to reproductive process in lesions on rice plants and disease forecast. Bulletin of the National Institute of Agriculture Science Service 28:1-61. 1974.

MACHADO, J.C. Padrões de tolerância de patógenos associados à semente. Revisão Anual de Patologia de Plantas 2:229-263. 1994.

OU, S.H. \& NUQUE, F. The relation between leaf and neck resistance to the rice blast disease. International Rice Commonwealth Newsletter 12:30-34. 1963.

PRABHU, A.S. \& FILIPPI, M.C. Age-mediated resistance and fungicide application for leaf blast control in upland rice. Tropical Pest Management 41:8-13. 1995.

PRABHU, A.S., SOAVE, J., ZIMMERMANN, F.J.P., FILIPPI, M.C., SOUZA, N.R.G., CURVO, R.C.V., LOPES, A.M., SOBRAL, C.A.M., FERREIRA, R.P., KOBAYASHI, T. \& GALVÃO, E.U.P. Genetic variability for disease resistance in Brazilian upland rice native germoplasm. Pesquisa Agropecuária Brasileira 31:413-424. 1996.

RANGASWAMI, G. \& SUBRAMANIAN, T.V. The correlation between the leaf and neck infections of the blast disease of rice. Indian Phytopathology 11:179-185. 1958.

ROUMEN, E.C. Effect of leaf age on components of partial resistance in rice to leaf blast. Euphytica 63:271-279. 1992a.

ROUMEN, E.C. Partial resistance to neck blast influenced by stage of panicle development and rice genotype. Euphytica 64:173-182. 1992b.

SILVA, L.H.C.P., MENEZES, C.C.E. \& LIELL, R.M. Avaliação da resistência de cultivares de trigo safrinha à brusone. Summa Phytopathologica 29:57. 2003. (Resumo).

URASHIMA, A.S., HASHIMOTO, Y., DON, L.D., KUSABA, M., TOSA, Y., NAKAYASHIKI, H. \& MAYAMA, S. Molecular analysis of the wheat blast population in Brazil with a homolog of retrotransposon MGR583. Annals of the Phytopathological Society of Japan, 65:429-436. 1999.

URASHIMA, A.S. \& KATO, H. Varietal resistance and chemical control of wheat blast fungus. Summa Phytopathologica 20:107-12. 1994.

URASHIMA, A.S. \& KATO, H. Pathogenic relationship between isolates of Pyricularia grisea of wheat and others hosts at different host developmental stages. Fitopatologia Brasileira 23:30-35. 1998.

WILLIS, G.M., ALLOWITZ, R.D. \& MENVILLE, E.S. Differential susceptibility of rice leaves and panicles to Pyricularia oryzae. Phytopathology 58:1072. 1968. (Abstract)

YANG, Y., WILSON, L.T., MAKELA, M.E., MARCHETTI, M.A. \& KRAUZ, J.P. Effect of leaf age and nodal position on receptivity of rice leaves to infection by Pyricularia grisea. Journal of Phytopathology 146:157-164. 1998.

ZHUANG, J.Y., MA, W.B., WU, J.L., CHAI, R.Y., LU, J., FAN, Y.Y., JIN, M.Z., LEUNG, H. \& ZHENG, K.L. Mapping of leaf and neck blast resistance genes with resistance gene analog, RAPD and RFLP in rice. Euphytica 128:363-370. 2002. 